in vivo $33: 1977-1984(2019)$

doi:10.21873/invivo.11693

\title{
Effect of Cardiac Expansion on Postsurgical Pulmonary Resection Recovery
}

\author{
YAMATO TAMURA ${ }^{1}$, NORIYOSHI SAWABATA ${ }^{1,2}$, YOSHIYUKI SUSAKI ${ }^{2}$, \\ TAKAHITO NAKAMURA ${ }^{3}$ and SHIGEKI TANIGUCHI ${ }^{1}$ \\ ${ }^{1}$ Department of Thoracic and Cardiovascular Surgery, Nara Medical University, Nara, Japan; \\ ${ }^{2}$ Department of Thoracic Surgery, Hoshigaoka Medical Center, Osaka, Japan; \\ ${ }^{3}$ Department of Respiratory Medicine, Hoshigaoka Medical Center, Osaka, Japan
}

\begin{abstract}
Background/Aim: In patients undergoing lung resection, even when lung and ventricular function are normal, there may be a prolonged delay in postoperative recovery. The effect of left ventricular extension disorders on recovery after pulmonary resection was investigated. Materials and Methods: The postoperative recovery of ninety patients with normal left ventricular ejection fraction and exercise tolerance who underwent anatomical pulmonary resection was evaluated according to the grade of left ventricular expansion (E/e'). Results: Left ventricular extension was normal $(\leq 8)$ in 53 cases, moderately restricted (8-12) in 36 cases and severely restricted (>12) in 9 cases. No significant difference was found in the postoperative complication rate. However, the severely restricted group had a significantly higher duration of oxygen administration, intensive care unit stay, and postoperative hospital stay, which were found to be independent predictors of ventricular expansion. Conclusion: Left ventricular expansion dysfunction had a negative effect on postoperative recovery.
\end{abstract}

Since lung and left ventricular contraction function limit exercise tolerance, they constitute an important factor when assessing the surgical risk of pulmonary resection $(1,2)$. However, even in cases of optimal exercise load, perioperative complications may occur and there may be a prolonged delay in postoperative recovery (3). Even if the left ventricular

This article is freely accessible online.

Correspondence to: Noriyoshi Sawabata, MD, Ph.D., Professor, Department of General Thoracic Surgery, Nara Medical University Hospital, 840 Shijo-cho, Kashihara, Nara, 634-8522, Japan. Tel: +81 744223051, Fax: +81 744248040, e-mail: nsawabata@ hotmail.com

Key Words: Cardiac expansion, pulmonary resection, postoperative recovery, left ventricular expansion. contraction function is maintained (ejection fraction, EF 0.45 to 0.50 or higher), left ventricular expansion failure increases the end-stage pressure of the left ventricle, leading to an increase in left atrial, pulmonary artery, pulmonary venous, and pulmonary capillary pressures, which may play a role in perioperative complications after pulmonary resection and cause a prolonged postoperative recovery (4). However, the effect of left ventricular expansion disorders on recovery after pulmonary resection has not been fully studied.

In this study, we examined whether cardiac expansion was a predictor of perioperative complications and postoperative recovery, in cases where both cardiac contractile function and exercise tolerance were maintained.

\section{Patients and Methods}

Background of patients. A total of 186 surgical cases of pulmonary tumour lesions were recorded at Hoshigaoka Medical Center between February 2015 and October 2017; 162 of these patients were able to climb from the first to the sixth floor $(22.2 \mathrm{~m})$ and 90 patients who underwent anatomical pulmonary resection for the treatment of lung cancer were enrolled in the study.

The baseline demographic and clinical data of the 90 cases are shown in Table I. As a rule, mediastinal lymph node resection was carried out in cases of lobectomy for lung cancer.

Postoperative management. Surgery was usually performed in the morning and patients were transferred to the intensive care unit (ICU) after surgery. If the circulation and the respiratory conditions were stable, the patient returned to the general ward in the next day and continued postoperative management. Oxygen administration was interrupted when $\% \mathrm{PaO}_{2} \geq 90 \%$ during walking and $\geq 93 \%$ or more with room air at rest. Discharge was allowed when sufficient performance of activities of daily living was achieved.

Echocardiography. Echocardiography was performed by a technician in the clinical laboratory using Aplio XG SSA-790A (TOSHIBA, Tokyo, Japan). EF (\%), tricuspid valve pressure gradient, and grade of ventricular expansion (E/e') values were collected as cardiac function evaluation items. 
Table I. Patient background data.

\begin{tabular}{|c|c|c|c|c|c|}
\hline \multirow[b]{2}{*}{ Variables } & \multirow[b]{2}{*}{ Whole } & \multicolumn{3}{|c|}{$\mathrm{E} / \mathrm{e}^{\prime}$} & \multirow[b]{2}{*}{$p$-Value } \\
\hline & & $\begin{array}{c}\text { Grade I } \\
<8\end{array}$ & $\begin{array}{c}\text { Grade II } \\
8-12\end{array}$ & $\begin{array}{l}\text { Grade III } \\
\quad>12\end{array}$ & \\
\hline $\mathrm{n}$ & 90 & 53 & 31 & 6 & \\
\hline Age (mean \pm S.D.) & $68.6 \pm 8.8$ & $67.1 \pm 9.4$ & $70.6 \pm 7.7$ & $71.2 \pm 7.7$ & 0.2 \\
\hline \multicolumn{6}{|l|}{ Gender } \\
\hline Male & 48 & 26 & 17 & 5 & 0.3 \\
\hline Female & 42 & 27 & 14 & 1 & \\
\hline BMI $\left(\mathrm{kg} / \mathrm{m}^{2}\right)($ mean \pm S.D. $)$ & $22.3 \pm 3.0$ & $22.2 \pm 3.1$ & $22.30 \pm 3.0$ & $22.7 \pm 1.7$ & 0.9 \\
\hline \multicolumn{6}{|l|}{ Disease } \\
\hline Lung cancer & 89 & 51 & 32 & 6 & 1.0 \\
\hline Metastasis & 1 & 1 & 0 & 0 & \\
\hline \multicolumn{6}{|l|}{ Comorbidities } \\
\hline No & 27 & 18 & 8 & 1 & 0.7 \\
\hline Yes & 63 & 35 & 23 & 5 & \\
\hline COPD & 31 & 20 & 9 & 2 & \\
\hline CPFE & 2 & 1 & 1 & 0 & \\
\hline IP & 3 & 2 & 1 & 0 & \\
\hline CVD & 29 & 11 & 14 & 4 & \\
\hline APO & 2 & 2 & 0 & 0 & \\
\hline DM & 11 & 6 & 4 & 1 & \\
\hline \multicolumn{6}{|c|}{ Respiratory function(mean \pm S.D.) } \\
\hline VC (L) & $3.3 \pm 0.5$ & $3.3 \pm 0.9$ & $3.2 \pm 0.8$ & $3.4 \pm 0.9$ & 0.6 \\
\hline$\% \mathrm{VC}(\%)$ & $109.8 \pm 18.3$ & $112.4 \pm 14.6$ & $109.8 \pm 12.6$ & $107.7 \pm 21.5$ & 0.6 \\
\hline FEV1 (L) & $2.3 \pm 0.6$ & $2.3 \pm 0.6$ & $2.2 \pm 0.5$ & $2.4 \pm 0.7$ & 0.6 \\
\hline$\%$ FEV1 $1 \%)$ & $104.1 \pm 21.6$ & $103.9 \pm 20.5$ & $104.3 \pm 20.6$ & $105.4 \pm 36.8$ & 1.0 \\
\hline FEV1\%(G) & $72.0 \pm 9.3$ & $72.0 \pm 10.2$ & $71.5 \pm 8.2$ & $73.1 \pm 6.7$ & 0.9 \\
\hline DLCO $(\mathrm{ml} / \mathrm{min} / \mathrm{mmHg})$ & $16.1 \pm 4.7$ & $16.9 \pm 4.7$ & $14.7 \pm 4.3$ & 16.65 .8 & 0.1 \\
\hline$\% \operatorname{DLCO}(\%)$ & $99.7 \pm 24.8$ & $103.2 \pm 26.3$ & $93.2 \pm 20.6$ & $101.4 \pm 28.0$ & 0.2 \\
\hline ppo\%FEV1 $(\%)$ & $84.0 \pm 19.4$ & $83.0 \pm 20.1$ & $84.9 \pm 16.2$ & $87.3 \pm 29.7$ & 0.8 \\
\hline ppo\%DLCO $(\%)$ & $79.7 \pm 23.9$ & $82.6 \pm 24.6$ & $73.5 \pm 21.2$ & $85.5 \pm 28.6$ & 0.2 \\
\hline \multicolumn{6}{|l|}{ Echocardiography } \\
\hline $\mathrm{EF}(\%)$ & $66.9 \pm 5.8$ & $67.5 \pm 5.9$ & $65.3 \pm 5.6$ & $69.7 \pm 4.5$ & 0.1 \\
\hline TRPG $(\mathrm{mmHg})$ & $15.3 \pm 12.9$ & $13.0 \pm 11.2$ & $19.1 \pm 14.9$ & $16.6 \pm 13.3$ & 0.1 \\
\hline $\mathrm{E} / \mathrm{e}^{\prime}$ & $8.1 \pm 2.3$ & $6.7 \pm 1.1$ & $9.5 \pm 1.2$ & $13.7 \pm 1.2$ & $<0.01$ \\
\hline $\mathrm{BNP}(\mathrm{pg} / \mathrm{ml})$ & $22.6 \pm 19.0$ & $20.3 \pm 19.6$ & $25.7 \pm 18.7$ & $27.65 \pm 13.3$ & 0.4 \\
\hline \multicolumn{6}{|l|}{ mMRC } \\
\hline 0 & 7 & 4 & 3 & 0 & 0.3 \\
\hline 1 & 79 & 47 & 27 & 5 & \\
\hline 2 & 2 & 1 & 1 & 0 & \\
\hline 3 & 1 & 0 & 0 & 1 & \\
\hline \multicolumn{6}{|l|}{$\mathrm{SpO} 2(\%)($ mean \pm S.D. $)$} \\
\hline Start at SCT & $97.4 \pm 0.9$ & $97.4 \pm 1.0$ & $97.4 \pm 0.8$ & $97.5 \pm 1.0$ & 0.9 \\
\hline End at SCT & $95.6 \pm 2.4$ & $95.6 \pm 2.5$ & $95.5 \pm 2.6$ & $95.8 \pm 0.5$ & 1.0 \\
\hline delta at SCT & $1.8 \pm 2.3$ & $1.7 \pm 2.4$ & $1.7 \pm 2.5$ & $1.2 \pm 1.0$ & 0.9 \\
\hline \multicolumn{6}{|l|}{ Pulmonary resection } \\
\hline Lob & 75 & 45 & 26 & 4 & \\
\hline Seg & 15 & 8 & 5 & 2 & \\
\hline
\end{tabular}

S.D.: Standard deviation; BMI: body mass index; COPD: chronic obstructive pulmonary disease; CPFE: chronic pulmonary fibrosis and emphysema; VC: vital capacity; FEV1: forced expiratory volume in the first second; DLCO: diffusing lung capacity for carbon monoxide; ppo: predicted postoperative; EF: ejection fraction; TRPG: tricuspid valve regurgitation pressure gradient; BNP: brain natriuretic peptide; mMRC: modified Medical Research Council; SCT: stair climbing test; Lob: lobectomy; Seg: segmentectomy.

Statistical analysis. E/e' was selected as an index of cardiac expansion and graded according to the classification of left ventricular expansion disorders of the American Echocardiography Society. E/e' $<8,8<$ E/e' $<12$, and $>12$ were defined as grade I, II, and
III, respectively (5). The chosen endpoints were the occurrence of complications, days of oxygen administration, length of ICU stay, and length of postoperative hospital stay. Complications were graded using the Clavien-Dindo (CD) classification (6). The 
Table II. Postoperative course according to the E/e' ratio.

\begin{tabular}{|c|c|c|c|c|}
\hline & \multicolumn{3}{|c|}{$\mathrm{E} / \mathrm{e}^{\prime}$} & \multirow[b]{2}{*}{$p$-Value } \\
\hline & $\begin{array}{c}\text { Grade I } \\
<8\end{array}$ & $\begin{array}{c}\text { Grade II } \\
8-12\end{array}$ & $\begin{array}{l}\text { Grade III } \\
\quad>12\end{array}$ & \\
\hline $\mathrm{n}$ & 53 & 31 & 6 & \\
\hline \multicolumn{5}{|l|}{ Complication grade* } \\
\hline Grade $>$ II & 5 & 4 & 2 & 0.2 \\
\hline Grade $>$ III & 3 & 1 & 1 & 0.4 \\
\hline Grade $>$ IV & 0 & 1 & 1 & 0.05 \\
\hline O2 supplementation (days) $($ mean \pm S.D. $)$ & $2.1 \pm 0.6$ & $4.5 \pm 12.6$ & $28.5 \pm 64.9$ & $<0.01$ \\
\hline ICU stay (days) (mean \pm S.D.) & $1.6 \pm 0.9$ & $1.6 \pm 1.3$ & $17.3 \pm 38.5$ & $<0.01$ \\
\hline Postoperative hospital stay (days) (mean \pm S.D.) & $10.7 \pm 7.9$ & $12.2 \pm 13.1$ & $36.7 \pm 61.1$ & $<0.01$ \\
\hline
\end{tabular}

*Clavien-Dindo classification grade (6); S.D.: standard deviation; ICU: intensive care unit.

Table III. Postoperative complications.

\begin{tabular}{|c|c|c|c|c|}
\hline & \multirow[b]{2}{*}{ Whole } & \multicolumn{3}{|c|}{$\mathrm{E} / \mathrm{e}^{\prime}$} \\
\hline & & Grade I & Grade II & Grade III \\
\hline & 11 & 5 & 4 & 2 \\
\hline \multicolumn{5}{|l|}{ Clavien-Dindo grade } \\
\hline Grade II & 6 & 2 & 3 & 1 \\
\hline Grade III & 3 & 3 & 0 & 0 \\
\hline Grade IV & 1 & 0 & 1 & 0 \\
\hline Grade V & 1 & 0 & 0 & 1 \\
\hline \multicolumn{5}{|l|}{ Complication } \\
\hline Lobe torsion & 1 & 1 & 0 & 0 \\
\hline Heart failure & 1 & 0 & 0 & 1 \\
\hline Arrythmia (AF) & 1 & 0 & 0 & 1 \\
\hline Intra thoracic hematoma & 1 & 0 & 1 & 0 \\
\hline Exacerbation of IP & 1 & 0 & 1 & 0 \\
\hline Chylothorax & 2 & 2 & 0 & 0 \\
\hline Delirium & 1 & 0 & 1 & 0 \\
\hline Deep vein thrombosis & 1 & 1 & 0 & 0 \\
\hline Prolonged air leak & 2 & 1 & 1 & 0 \\
\hline
\end{tabular}

AF: Atrial fibrillation; IP: interstitial pneumonia.

distribution of frequency of CD classification $>$ II, $>$ III, and $>$ IV was tested using the chi-square test. When a significant difference was observed, the hazard ratio was determined using a multivariate logistic regression analysis. Differences in the length of oxygen administration, ICU stay, and postoperative hospital stay were tested using a one-way ANOVA. In addition, when significant differences were observed in the univariate analysis, multivariate analysis was performed using those variables. In all statistical assessments, a $p$ value $<0.05$ was defined as statistically significant. Statistical analyses were performed using the statistics software 'EZR', which is based on $\mathrm{R}$ and $\mathrm{R}$ commander (7).

Ethical approval. This study was approved by the institutional review board of the Hoshigaoka Medical Center (No.19046) and patients had the opportunity to opt-out of the study.

\section{Results}

E/e' grade and baseline patient characteristics. As shown in Table I, no significant differences were found between the three groups (Grade I, Grade II and Grade III) regarding average age, sex, disease, surgical procedure, comorbidities, shortness of breath, pulmonary function testing, cardiac echocardiography findings, and B-type atrial natriuretic peptide (BNP) levels.

Postoperative course. Results of the comparison between the three groups regarding postoperative complications, oxygen administration period, length of ICU and postoperative hospital 
Table IV. Analyses based on the oxygen supply period.

\begin{tabular}{|c|c|c|c|c|c|c|}
\hline Variables & RCE & \multicolumn{2}{|c|}{$95 \% \mathrm{CI}$} & S.E. & $\mathrm{t}$ & $p$-Value \\
\hline \multicolumn{7}{|l|}{ Univariate analysis } \\
\hline Age $($ mean \pm S.D.) & 0.33 & -0.10 & 0.76 & 0.22 & 1.52 & 0.13 \\
\hline \multicolumn{7}{|l|}{ Gender } \\
\hline Male & 5.04 & -2.59 & 12.67 & 3.83 & 1.31 & 0.19 \\
\hline BMI $\left(\mathrm{kg} / \mathrm{m}^{2}\right)($ mean \pm S.D. $)$ & -2164.16 & -15319.48 & 11063.16 & 6654.89 & -0.32 & 0.75 \\
\hline \multicolumn{7}{|l|}{ Comorbidity } \\
\hline Yes & 3.47 & -4.88 & 11.82 & 4.20 & 0.83 & 0.41 \\
\hline \multicolumn{7}{|c|}{ Respiratory function (mean \pm S.D.) } \\
\hline $\mathrm{VC}(\mathrm{L})$ & -3.14 & -7.76 & 1.47 & 2.32 & -1.35 & 0.18 \\
\hline$\% \mathrm{VC}(\%)$ & -0.41 & -0.67 & -0.16 & 0.13 & -3.20 & $<0.01$ \\
\hline FEV1 (L) & -5.95 & -12.66 & 0.77 & 3.38 & -1.76 & 0.08 \\
\hline$\%$ FEV1 $1 \%)$ & -0.22 & -0.40 & -0.05 & 0.09 & -2.51 & 0.01 \\
\hline FEV $1 \%(\mathrm{G})$ & -0.15 & -0.57 & 0.28 & 0.21 & -0.69 & 0.49 \\
\hline DLCO $(\mathrm{ml} / \mathrm{min} / \mathrm{mmHg})$ & -0.53 & -1.35 & 0.30 & 0.41 & -1.27 & 0.21 \\
\hline$\% \operatorname{DLCO}(\%)$ & -0.02 & -0.17 & 0.14 & 0.08 & -0.19 & 0.85 \\
\hline ppo\%FEV1 $(\%)$ & -0.19 & -9.39 & 1.27 & 0.09 & -1.99 & 0.05 \\
\hline ppo\%DLCO $(\%)$ & 0.01 & -1.52 & 0.17 & 0.01 & 0.11 & 0.91 \\
\hline \multicolumn{7}{|l|}{ Echocardiography findings } \\
\hline $\mathrm{EF}(\%)$ & 0.30 & -0.39 & 0.99 & 0.35 & 0.86 & 0.39 \\
\hline TRPG (mmHg) & 2.00 & -0.12 & 0.51 & 0.16 & 1.25 & 0.21 \\
\hline \multicolumn{7}{|l|}{ E/e' grade } \\
\hline I & Ref. & & & & & \\
\hline II & 2.47 & -5.28 & 10.22 & 3.90 & 0.63 & 0.53 \\
\hline III & 26.42 & 11.66 & 41.18 & 7.43 & 3.56 & $<0.01$ \\
\hline $\mathrm{BNP}(\mathrm{pg} / \mathrm{ml})$ & 0.08 & -0.12 & 0.29 & 0.10 & 0.82 & 0.42 \\
\hline mMRC & 25.36 & 16.70 & 34.03 & 4.36 & 5.82 & $<0.01$ \\
\hline \multicolumn{7}{|l|}{$\mathrm{SpO}_{2}(\%)($ mean \pm S.D. $)$} \\
\hline Start at SCT & 1.90 & -2.70 & 6.50 & 2.31 & 0.83 & 0.41 \\
\hline End at SCT & -0.56 & -2.28 & 1.16 & 0.86 & -0.65 & 0.51 \\
\hline Change at SCT & 0.87 & -0.77 & 2.52 & 0.83 & 1.05 & 0.29 \\
\hline Pulmonary resection & Seg & 9.65 & -0.45 & 19.76 & 5.09 & 1.900 .06 \\
\hline \multicolumn{7}{|l|}{ Multivariate analysis } \\
\hline$\% \mathrm{VC}(\%)$ & -0.26 & -0.51 & -0.01 & 0.13 & -2.07 & 0.04 \\
\hline$\%$ FEV1 $1 \%)$ & -0.09 & -0.26 & 0.07 & 0.08 & -1.13 & 0.26 \\
\hline \multicolumn{7}{|l|}{ E/e' grade } \\
\hline I & Ref. & & & & & \\
\hline II & 1.96 & -4.62 & 8.55 & 3.11 & 0.59 & 0.60 \\
\hline III & 17.10 & 4.16 & 30.03 & 6.50 & 2.63 & 0.01 \\
\hline mMRC & 21.02 & 12.64 & 29.40 & 4.22 & 4.99 & $<0.01$ \\
\hline
\end{tabular}

RCE: Regression coefficient estimate; S.D.: standard deviation; CI: confidence interval; BMI: body mass index; mMRC: modified Medical Research Council; RFT: respiratory function test; VC: vital capacity; FEV1: forced expiratory volume during the first second; DLCO: diffusing lung capacity for carbon monoxide; ppo: predicted postoperative; EF: ejection fraction; TRPG: tricuspid valve regurgitation pressure gradient; BNP: brain natriuretic peptide; seg: segmentectomy.

stay are shown in Table II. There were $6,4,1$, and 1 cases of grade II, III, IV, and V complications, respectively (Table III), with no significant difference between the three groups in the distribution of $\mathrm{CD}$ classification. However, the p-value was 0.05 for the threshold of CD classification grade IV. On the other hand, a significant difference was found between the three groups in the length of oxygen administration, ICU stay, and postoperative hospital stay. Using the CD classification grade II, III, and >IV or more as the endpoint, in a logistic regression analysis with the E/e' grades as variable, there was no significant difference in endpoints of CD classification. Results of the logistic regression analysis with the length of oxygen supplementation, ICU stay, and postoperative hospital stay are shown in Tables IV, V, and VI, respectively. E/e' grade was the independent variable in all multivariate analyses.

\section{Discussion}

Even if the left ventricular contraction function is normal and exercise tolerance is maintained, a ventricular expansion 
Table V. Analyses based on the length of ICU stay.

\begin{tabular}{|c|c|c|c|c|c|c|}
\hline Variables & RCE & & & S.E. & $\mathrm{t}$ & $p$-Value \\
\hline \multicolumn{7}{|l|}{ Univariate analysis } \\
\hline Age $(m e a n \pm$ S.D.) & 0.10 & -0.14 & 0.34 & 0.12 & 0.85 & 0.85 \\
\hline \multicolumn{7}{|l|}{ Gender } \\
\hline Male & 2.04 & -2.17 & 6.24 & 2.11 & 0.96 & 0.33 \\
\hline BMI $\left(\mathrm{kg} / \mathrm{m}^{2}\right)($ mean \pm S.D. $)$ & -1196.82 & -8458.12 & 6058.48 & 3650.26 & -0.33 & 0.74 \\
\hline \multicolumn{7}{|l|}{ Comorbidity } \\
\hline Yes & 1.43 & -3.16 & 6.02 & 2.31 & 0.62 & 0.54 \\
\hline \multicolumn{7}{|c|}{ Respiratory function(mean \pm S.D.) } \\
\hline $\mathrm{VC}(\mathrm{L})$ & -1.83 & -4.36 & 0.70 & 1.27 & -1.43 & 0.15 \\
\hline$\% \mathrm{VC}(\%)$ & -0.22 & -0.36 & -0.08 & 0.07 & -3.12 & $<0.01$ \\
\hline FEV1 (L) & -3.67 & -7.34 & 0.00 & 1.85 & -1.99 & 0.05 \\
\hline$\%$ FEV1 $(\%)$ & -0.07 & -0.12 & -0.01 & 0.03 & -2.42 & 0.02 \\
\hline FEV1\%(G) & -0.05 & -0.17 & 0.07 & 0.06 & -0.88 & 0.38 \\
\hline DLCO $(\mathrm{ml} / \mathrm{min} / \mathrm{mmHg})$ & -0.08 & -0.34 & 0.17 & 0.13 & -0.63 & 0.53 \\
\hline$\% \operatorname{DLCO}(\%)$ & 0.02 & -0.07 & 0.10 & 0.04 & 0.39 & 0.70 \\
\hline ppo\%FEV1 $(\%)$ & -0.11 & -0.06 & 0.00 & 0.05 & -2.07 & 0.04 \\
\hline ppo\%DLCO (\%) & 0.03 & -0.06 & 0.11 & 0.05 & 0.58 & 0.56 \\
\hline \multicolumn{7}{|l|}{ Echocardiography findings } \\
\hline $\mathrm{EF}(\%)$ & 0.19 & -0.18 & 0.58 & 0.19 & 1.03 & 0.30 \\
\hline TRPG $(\mathrm{mmHg})$ & 0.08 & -0.09 & 0.25 & 0.09 & 0.94 & 0.35 \\
\hline \multicolumn{7}{|l|}{ E/e' grade } \\
\hline I & Ref. & & & & & \\
\hline II & 0.10 & -4.08 & 4.27 & 2.10 & 0.05 & 0.96 \\
\hline III & 15.79 & 7.83 & 23.75 & 4.00 & 4.94 & $<0.01$ \\
\hline $\mathrm{BNP}(\mathrm{pg} / \mathrm{ml})$ & 0.05 & -0.06 & 0.16 & 0.06 & 0.86 & 0.39 \\
\hline mMRC & 15.03 & 10.43 & 19.63 & 2.31 & 6.50 & $<0.01$ \\
\hline \multicolumn{7}{|l|}{ SpO2 (\%) (mean \pm S.D.) } \\
\hline Start at SCT & 0.95 & -1.58 & 3.47 & 1.27 & 0.75 & 0.46 \\
\hline End at SCT & 0.13 & -0.81 & 1.07 & 0.47 & 0.27 & 0.78 \\
\hline Change at SCT & 0.01 & -0.90 & 0.92 & 0.45 & 0.02 & 0.98 \\
\hline \multicolumn{7}{|l|}{ Pulmonary resection } \\
\hline Seg & 6.28 & 0.78 & 11.78 & 2.75 & 2.27 & 0.02 \\
\hline \multicolumn{7}{|l|}{ Multivariate analysis } \\
\hline$\% \mathrm{VC}(\%)$ & -0.14 & -0.26 & 0.01 & 0.06 & -2.11 & 0.03 \\
\hline$\%$ FEV1 $(\%)$ & 1.95 & 0.36 & 3.56 & 0.81 & 2.41 & 0.02 \\
\hline ppo\%FEV1 (\%) & -2.43 & -4.40 & -0.48 & 0.98 & -2.48 & 0.02 \\
\hline \multicolumn{7}{|l|}{ E/e' grade } \\
\hline I & Ref. & & & & & \\
\hline II & -0.23 & -3.52 & 3.07 & 1.66 & -0.14 & 0.80 \\
\hline III & 10.09 & 3.56 & 16.62 & 3.28 & 3.07 & $<0.01$ \\
\hline mMRC & 10.12 & 5.52 & 14.72 & 2.31 & 4.37 & $<0.01$ \\
\hline Seg & 27.04 & 7.74 & 46.34 & 9.70 & 2.79 & $<0.01$ \\
\hline
\end{tabular}

RCE: Regression coefficient estimates; S.D.: standard deviation; CI: confidence interval; BMI: body mass index; mMRC: modified Medical Research Council; RFT: respiratory function test; VC: vital capacity; FEV1: forced expiratory volume during the first second; DLCO: diffusing lung capacity for carbon monoxide; ppo: predicted postoperative; EF: ejection fraction; TRPG: tricuspid valve regurgitation pressure gradient; BNP: brain natriuretic peptide; seg: segmentectomy.

disorder may still be present (4). Pulmonary resection is said to have a negative effect on left ventricular expansion. If there is a cardiac expansion disorder, the end-stage left ventricular diastolic pressure increases, as do the left atrium, pulmonary artery, pulmonary venous, and pulmonary capillary pressures, resulting in pulmonary congestion and oedema (4). Since pulmonary resection causes pulmonary vascular reduction, a reduced left ventricular expansion may affect the postoperative recovery. Indeed, it has been reported that E/e', an indicator of cardiac extension measured by echocardiography, is a predictor of upper ventricular arrhythmia appearance after pulmonary resection $(8,9)$.

The most important risk in the perioperative period is the occurrence of complications. Predictors of complications 
Table VI. Analysis based on the length of postoperative hospital stay.

\begin{tabular}{|c|c|c|c|c|c|c|}
\hline Variables & RCE & & & S.E. & t statics & $p$-Value \\
\hline \multicolumn{7}{|l|}{ Univariate analysis } \\
\hline Age (mean \pm S.D.) & 0.21 & -0.23 & 0.65 & 0.22 & 0.94 & 0.35 \\
\hline \multicolumn{7}{|l|}{ Gender } \\
\hline Male & 7.49 & -0.2 & 16.17 & 3.87 & 1.94 & 0.06 \\
\hline BMI $\left(\mathrm{kg} / \mathrm{m}^{2}\right)($ mean \pm S.D. $)$ & -5538.98 & -18958 & 7880.01 & 6751.32 & -0.82 & 0.41 \\
\hline \multicolumn{7}{|l|}{ Comorbidities } \\
\hline Yes & 4.42 & -4.07 & 12.9 & 4.27 & 1.03 & 0.3 \\
\hline \multicolumn{7}{|c|}{ Respiratory function(mean \pm S.D.) } \\
\hline $\mathrm{VC}(\mathrm{L})$ & -1.09 & 0.51 & 32.64 & 2.38 & -0.45 & 0.65 \\
\hline$\% \mathrm{VC}(\%)$ & -0.34 & -0.61 & -0.08 & 0.13 & -2.56 & 0.01 \\
\hline FEV1 (L) & -3.43 & -10.35 & 3.49 & 3.48 & -0.99 & 0.33 \\
\hline$\%$ FEV1 $1 \%)$ & -0.24 & -0.41 & -0.06 & -0.09 & -2.64 & $<0.01$ \\
\hline FEV $1 \%(\mathrm{G})$ & -0.25 & -0.68 & 0.18 & 0.21 & -1.17 & 0.25 \\
\hline $\mathrm{DLCO}(\mathrm{ml} / \mathrm{min} / \mathrm{mmHg})$ & -0.37 & -1.2 & 0.47 & 0.42 & -0.87 & 0.38 \\
\hline$\% \operatorname{DLCO}(\%)$ & -0.02 & -0.18 & 0.14 & 0.08 & -0.3 & 0.76 \\
\hline ppo\%FEV1 (\%) & -0.21 & -0.4 & -0.01 & 0.1 & -2.06 & 0.04 \\
\hline ppo\%DLCO (\%) & -4 & -0.2 & 0.13 & 0.08 & -0.46 & 0.65 \\
\hline \multicolumn{7}{|l|}{ Echocardiography findings } \\
\hline $\mathrm{EF}(\%)$ & 0.08 & -0.62 & 0.78 & 0.36 & 0.23 & 0.82 \\
\hline TRPG $(\mathrm{mmHg})$ & 0.11 & -0.21 & 0.43 & 0.16 & 0.71 & 0.48 \\
\hline \multicolumn{7}{|l|}{ E/e' grade } \\
\hline I & Ref. & & & & & \\
\hline II & 1.44 & -6.48 & 9.37 & 3.99 & 0.36 & 0.72 \\
\hline III & 25.95 & 10.85 & 41.48 & 7.6 & 3.42 & $<0.01$ \\
\hline $\mathrm{BNP}(\mathrm{pg} / \mathrm{ml})$ & 0.16 & -0.04 & 0.36 & 0.1 & 1.56 & 0.12 \\
\hline mMRC & 25.04 & 16.13 & 33.96 & 4.49 & 5.58 & $<0.01$ \\
\hline \multicolumn{7}{|l|}{ SpO2 (\%) (mean \pm S.D. $)$} \\
\hline Start at SCT & 3.08 & -1.49 & 7.66 & 2.3 & 1.34 & 0.18 \\
\hline End at SCT & -0.35 & -2.07 & 1.38 & 0.87 & -0.4 & 0.69 \\
\hline Change at SCT & 0.72 & -0.97 & 2.4 & 0.85 & 0.85 & 0.4 \\
\hline \multicolumn{7}{|l|}{ Pulmonary resection } \\
\hline Seg & 8.15 & -2.21 & 18.5 & 5.21 & 1.56 & 0.12 \\
\hline \multicolumn{7}{|l|}{ Multivariate analysis } \\
\hline$\% \mathrm{VC}(\%)$ & -0.15 & -0.41 & 0.11 & 0.13 & -1.13 & 0.26 \\
\hline$\%$ FEV1 $(\%)$ & -0.3 & -1.03 & 0.44 & 0.37 & -0.81 & 0.42 \\
\hline ppo\%FEV1 (\%) & 0.19 & -0.71 & 1.01 & 0.45 & 0.42 & 0.67 \\
\hline \multicolumn{7}{|l|}{ E/e' grade } \\
\hline I & Ref. & & & & & \\
\hline II & 1.16 & -5.78 & 8.1 & 3.49 & 0.33 & 0.73 \\
\hline III & 16.91 & 3.18 & 30.94 & 6.9 & 2.45 & 0.03 \\
\hline mMRC & 20.91 & 12.02 & 29.8 & 4.47 & 4.68 & $<0.01$ \\
\hline
\end{tabular}

RCE: Regression coefficient estimates; S.D.: standard deviation; CI: confidential interval; BMI: body mass index; mMRC: modified Medical Research Council; RFT: respiratory function test; VC: vital capacity; FEV1: forced expiratory volume during the first second; DLCO: diffusing lung capacity for carbon monoxide; ppo: predicted postoperative; EF: ejection fraction; TRPG: tricuspid valve regurgitation pressure gradient; BNP: brain natriuretic peptide; seg: segmentectomy.

include the extent of pulmonary resection, lung function, and exercise tolerance $(1,2)$. All patients enrolled in the study underwent anatomical pulmonary resection, had normal left ventricular contraction function (i.e., normal surgical risk) and were able to walk up six floors $(22.2 \mathrm{~m})$ in the stair climbing test. However, although no significant difference was observed in the frequency of complications with a CD grade IV or V; given that complications tend to occur when the E/e' ratio is high, heart expansion disorders may still affect postoperative recovery.

The length of postoperative oxygen administration, ICU stay, and postoperative hospital stay are affected by the preoperative cardiopulmonary function. The duration of oxygen administration period is a particularly relevant factor. This is because in cases of pulmonary resection, the refilling phenomenon could lead to increased pulmonary capillary 
pressure, resulting in the need for oxygen supplementation (10). In fact, in our study, there was no significant difference in the length of oxygen administration between patients with normal and moderately limited left ventricular expansion, but the opposite was seen in the comparison with patients with advanced left ventricular extension disorder. Similar results were found for the length of ICU stay and the postoperative hospitalization period. This may indicate that left ventricular expansion disorders may have an effect not only during the immediate postoperative recovery, but also in the long-term, affecting vital prognosis.

Left ventricular expansion declines with age (11), which may be due to age-dependent cardiac tissue functional decrease $(12,13)$. Therefore, in the older population, there is a high risk of complications in the postoperative course. In fact, in a study of lung resection cases as treatment for lung cancer in patients over 80 years old, the pulmonary resection volume was found to be associated with the frequency of non-lung cancer deaths (14). In older patients with normal lung function, activity levels, and exercise tolerance, standard pulmonary resection is often selected in the case of invasive lung cancer. However, there are no reports on the usefulness of evaluating left ventricular extension when determining the pulmonary resection volume in older patients.

Further prospective studies should be carried out to determine whether left ventricular expansion at baseline is related to vital prognosis in older patients.

The limitations of this study are that it was a single-centre retrospective study with a small sample. However, since left ventricular contraction function and exercise tolerance were normal in all patients who underwent anatomical pulmonary resection, bias due to differences in background characteristics was considered small.

In conclusion, in patients with normal left ventricular contraction and exercise tolerance who undergo anatomical pulmonary resection, left ventricular expansion dysfunction had a negative effect on postoperative recovery.

\section{Conflicts of Interest}

The Authors have no conflicts of interest to declare regarding this study.

\section{Acknowledgements}

The Authors would like to thank Editage (www.editage.com) for English language editing.

\section{Authors' Contributions}

Yamato Tamura: data analysis; Noriyoshi Sawabata: data collection; Yoshiyuki Susaki: review and revision of the manuscript; Takahito Nakamura: data collection; Shigeki Tniguchi: supervision.

\section{References}

1 Brunelli A, Kim AW, Berger KI and Addrizzo-Harris DJ: Physiologic evaluation of the patient with lung cancer being considered for resectional surgery: Diagnosis and management of lung cancer, 3rd ed: American College of Chest Physicians Evidence-based Clinical Practice Guidelines. Chest 143(5 Suppl): e166S-e90S, 2013. PMID: 23649437. DOI: 10.1378/chest.122395

2 Sawabata N, Nagayasu T, Kadota Y, Goto T, Horio H, Mori T, Yamashita $\mathrm{S}$ and Iwasaki A: Risk assessment of lung resection for lung cancer according to pulmonary function: republication of systematic review and proposals by guideline committee of the Japanese association for chest surgery 2014. Gen Thorac Cardiovasc Surg 63(1): 14-21, 2015. PMID: 25257966. DOI: 10.1007/s 11748-014-0475-x

3 Nakamura T, Sawabata N, Susaki Y and Muro S: Desaturation during the stair-climbing test for patients who will undergo pulmonary resection: an indicator of postoperative complications. Gen Thorac Cardiovasc Surg, 2019. PMID: 31165435. DOI: 10.1007/s11748-019-01153-z

4 Zile MR and Brutsaert DL: New concepts in diastolic dysfunction and diastolic heart failure: Part I: diagnosis, prognosis, and measurements of diastolic function. Circulation 105(11): 13871893, 2002. PMID: 11901053. DOI: $10.1161 / \mathrm{hc} 1102.105289$

5 Nagueh SF, Smiseth OA, Appleton CP, Byrd BF 3rd, Dokainish H, Edvardsen T,Flachskampf FA, Gillebert TC, Klein AL, Lancellotti P, Marino P, Oh JK, Popescu BA and Waggoner AD: Recommendations for the evaluation of left ventricular diastolic function by echocardiography: an update from the American society of echocardiography and the European Association of Cardiovascular Imaging. J Am Soc Echocardiogr 29(4): 277-314, 2016. PMID: 27037982. DOI: 10.1016/j.echo.2016.01.011

6 Dindo D, Demartines N and Clavien PA: Classification of surgical complications: a new proposal with evaluation in a cohort of 6336 patients and results of a survey. Ann Surg 240(2): 205-213, 2004. PMID: 15273542. DOI: 10.1097/01.sla.0000133083.54934.ae

7 Kanda Y: Investigation of the freely available easy-to-use software 'EZR' for medical statistics. Bone Marrow Transplant 48(3): 452458, 2013. PMID: 23208313. DOI: 10.1038/bmt.2012.244

8 Nojiri T, Maeda H, Takeuchi Y, Funakoshi Y, Maekura R, Yamamoto $\mathrm{K}$ and Okumura M: Predictive value of preoperative tissue Doppler echocardiographic analysis for postoperative atrial fibrillation after pulmonary resection for lung cancer. $\mathbf{J}$ Thorac Cardiovasc Surg 140(4): 764-768, 2010. PMID: 20691999. DOI: $10.1016 /$ j.jtcvs.2009.11.073

9 Iwata $\mathrm{T}$, Nagato K, Nakajima T, Suzuki H, Yoshida $\mathrm{S}$ and Yoshino I: Risk factors predictive of atrial fibrillation after lung cancer surgery. Surg Today 46(8): 877-886, 2016. PMID: 26471506. DOI: $10.1007 / \mathrm{s} 00595-015-1258-4$

10 Nojiri T, Yamamoto K, Maeda H, Takeuchi Y, Funakoshi Y, Inoue $\mathrm{M}$ and Okumura $\mathrm{M}$ : Effect of low-dose human atrial natriuretic peptide on postoperative atrial fibrillation in patients undergoing pulmonary resection for lung cancer: a doubleblind, placebo-controlled study. J Thorac Cardiovasc Surg 143(2): 488-494, 2012. PMID: 21992849. DOI: 10.1016/ j.jtcvs.2011.09.003

11 De Sutter J, De Backer J, Van de Veire N, Velghe A, De Buyzere $\mathrm{M}$ and Gillebert TC: Effects of age, gender, and left ventricular 
mass on septal mitral annulus velocity (E') and the ratio of transmitral early peak velocity to E' (E/E'). Am J Cardiol 95(8): 1020-1023, 2005. PMID: 15820183. DOI: 10.1016/j.amjcard. 2005.01 .021

$12 \mathrm{Li} \mathrm{Y}$, Asfour $\mathrm{H}$ and Bursac N: Age-dependent functional crosstalk between cardiac fibroblasts and cardiomyocytes in a 3D engineered cardiac tissue. Acta Biomater 55: 120-130, 2017. PMID: 28455218. DOI: 10.1016/j.actbio.2017.04.027

13 Meschiari CA, Ero OK, Pan H, Finkel T and Lindsey ML: The impact of aging on cardiac extracellular matrix. Geroscience 39(1): 7-18, 2017. PMID: 28299638. DOI: 10.1007/s11357-0179959-9
14 Okami J, Higashiyama M, Asamura H, Goya T, Koshiishi Y, Sohara Y, Eguchi K, Mori M, Nakanishi Y, Tsuchiya R, Miyaoka E and Japanese Joint Committee of Lung Cancer Registry: Pulmonary resection in patients aged 80 years or over with clinical stage I non-small cell lung cancer: prognostic factors for overall survival and risk factors for postoperative complications. J Thorac Oncol 4(10): 1247-1253, 2009. PMID: 19609223. DOI: 10.1097/JTO.0b013e3181ae285d

Received July 6, 2019

Revised August 29, 2019

Accepted September 3, 2019 